\title{
Operating Reserves Adequacy in Future Pakistan Power System
}

\author{
Zafar Ahmad ${ }^{1}$, Syed Afzal Shah ${ }^{2}$, Israr Uddin ${ }^{3}$ \\ ${ }^{1,2,3}$ Department of Electrical Energy System Engineering, US-Pakistan Center for Advanced Studies in Energy \\ (USPCAS-E), UET, Peshawar, Pakistan \\ zafar.ahmad619@gmail.com¹, afxalshaw@gmail.com², israreng93@gmail.com ${ }^{3}$ \\ Received: 09 December, Revised: 19 December, Accepted: 25 December
}

\begin{abstract}
In this paper estimation of PFC (Primary frequency control) reserves and their adequacy has been investigated. Since Pakistan is aiming to add more renewable generation to its power system to reduce their dependency on fossil fuels and because of their concern about the environmental polution. And this renewable penetration adds variability and complexity to the power grid and doesn't add inertia to the system. So therefore overall inertia of the system decreases in result of addition of renewables. When the inertia of the system decreases, frequency deviations increases because of the renewable forecast error and other contingencies in the grid. To study thiese frequency deviations expected scenario for Pakistan power system are created for current and future Pakistan power system. From these studies, estimation of PFC reserves are made in this paper for future Pakistan power system. This paper also explain the frequency instability arises due to high renewable integration in power system and their feasible solutions for future Pakistan power system.
\end{abstract}

Keywords - PFC reserves, Renewable penetration, frequency deviations, inertia, power system

\section{INTRODUCTION}

Reliability and security of a power system depends on the stability of frequency of the whole system. For frequency to be stable within range of $50 \mathrm{~Hz} \pm 0.1 \%$ [1], load and generation of a power system must be balanced. Any mismatches between load and generation cause deviation in frequency. Now a days Pakistan is also trying to increase renewable penetration in its power system. Since renewable generation is variable in nature and it adds variability and uncertainty to the power system and in turn cause frequency deviation in the system and system becomes weak and more vulnerable to contingencies and these uncertainities arises due to renewable forcast error like wind forecast error and solar forecast error which we need hour ahead or more than one hour forecast data. To cope with these uncertainties, we need operating reserves in the power system, both manual and automatic reserves.

Operating reserves are of several types, in UCTE (Union for Co-ordination of Transmission of Electricity) [2], several reserves were named as (PFCR) primary frequency control reserves, (SFCR) secondary frequency control reserves and tertiary reserves.

Primary reserves are also called as FCR (Frequency containment reserves), secondary reserves are called as FRR (Frequency Restoration reserves) and tertiary reserves are called as RR replacement reserves according to their functions [3]. These operating reserves are called upon by different names in different countries according to their functions. Operating reserves and their different types are given in details in figure 1.

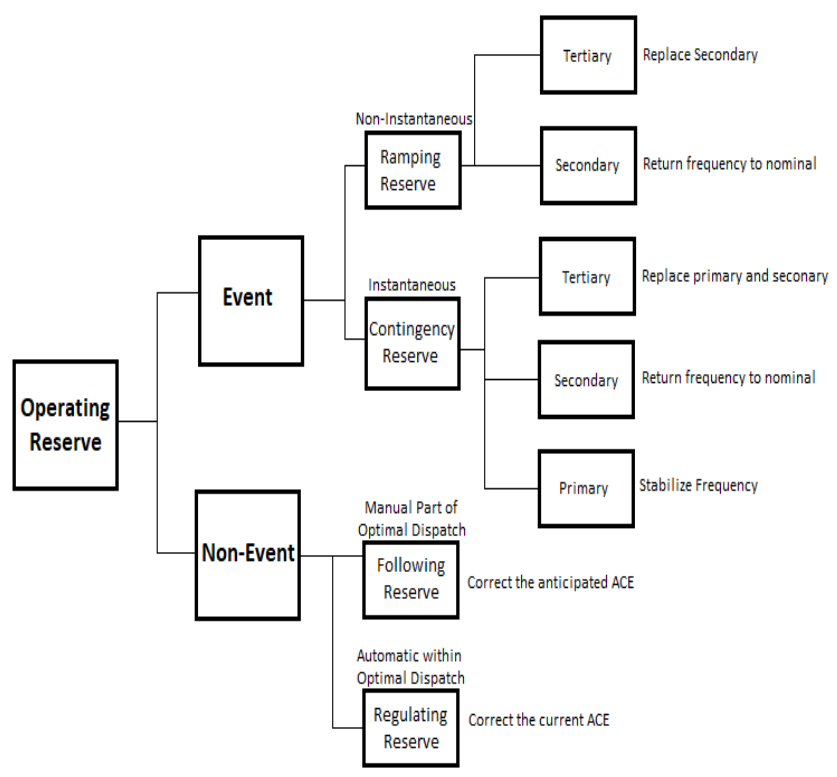

Figure 1. Classification of operating reserves

First of all, when any contingency appear on the system primary reserves are activated automatically to catch frequency deviation as fast as possible and keep it stable at some point below its reference value. Then secondary control reserves are activated to bring back frequency to its nominal value and tertiary reserves are activated to replace secondary reserves and to stabilize the power system. Activation manner of operating reserves are presented in figure 2 . 


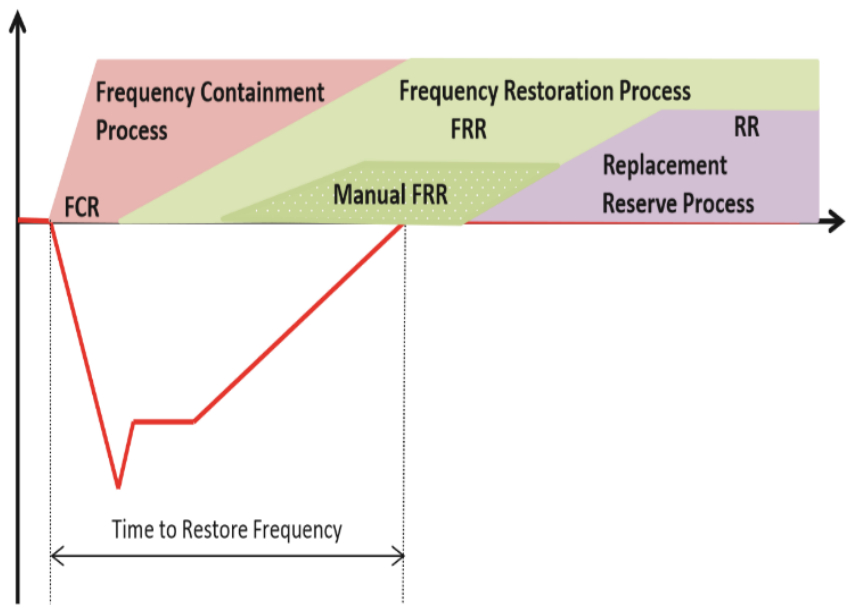

Figure 2. Operating reserves activation order

\section{RELATED WORK}

In [4] author's have explained about different types of operating reserves and their need in power system as renewable integration increases day by day. Author's have explained how these reserves control the disturbances in the power system arises due to sudden generation loss, sudden load loss and renewable forecast error. They have also discussed how in future these reserves can be used in a power system due to increase penetration of renewables. It also explains how much reserves are required for the power system after a detail study of that system and to allocate the suitable amount of reserves for that power system. They have also classified these reserves according to their functions.

In [5] this paper author has presented different power scenarios for European power system and author has also recorded the forecasted values of wind for different times. But the main objective of this paper is to observe the primary reserve adequacy along with secondary reserves in Europe future power scenarios. this research also explains the difficulties arises due to renewable forecast error and present possible solution to these challenges.

In [6] author have presented a study of high wind power penetrated system and replacement of conventional generation by renewable power generation and its impact on inertia of the system. And impact on frequency of the power system due to decrease in inertia of the system. This research also discusses the ability of wind turbines to deliver backing during contingencies to avoid any unwanted situations. It also explains wind power penetration to its maximum possible level without causing any instability to the system.

\section{FREQUENCY RESPONSE TO ASSESS PFC RESERVES}

Since renewable penetration is variable in nature and adds variability to the power system, therefore it has a huge impact on operating reserves. As renewable penetration increases in a power system, demand for operating reserves increases to cater with frequency deviation arises due to variability of renewable generation. Now if after a sudden contingency on a power system the availability of the power to customers in not interrupted, then we can say the primary reserves are enough. For this to evaluate either reserves are enough or not in the system we have responses of frequency, one is frequency nadir and PFC [7].

\section{A. Inertia of System}

Inertia of a system can be defined as the opposition to frequency deviation provided by the rotating mass of the system. Inertia of a system can be represented as

$$
M=\frac{2 H S}{f} \approx \frac{2 H S}{f_{0}}=\frac{2 H_{e q} P_{\text {Generation, }}}{f_{0}}
$$

Where $\mathrm{P}$ _Generation is power of the system, $\mathrm{S}$ is apparent power, $\mathrm{H}$ is inertia constant, fo is reference frequency and $\mathrm{f}$ is frequency of the system. Inertia constant are different for different kind of generating units, it may be different for hydro generating unit and may be different for steam generating unit. Renewable generation doesn't add inertia to the system. Figure 3 below shows different generating units and its constant of inertia $\mathrm{H}[8]$.

\begin{tabular}{|l|l|}
\hline Type of generation unit & $\mathrm{H}$ \\
\hline Thermal unit & \\
(a) $3600^{4} \mathrm{r} / \mathrm{min}$ (2 pole) & 2.5 to 6.0 \\
(b) $1800^{5} \mathrm{r} / \mathrm{min}$ (4 pole) & 4.0 to 10.0 \\
\hline Hydraulic unit & 2.0 to 4.0 \\
\hline
\end{tabular}

Figure 3. Inertia Constant values of generating units [1]

$\mathrm{H}$ for a single generating unit is given by

$$
H=\frac{1}{2} \frac{J \omega_{\mathrm{n}}^{2}}{S_{\mathrm{n}}}[\mathrm{s}]
$$

Where $\mathbf{J}$ is moment of inertia, where $\mathrm{w}_{\mathrm{n}}$ represents angular mechanical velocity and $S_{n}$ is apparent power. Now to calculate the inertia of the whole system, rated power and constant of inertia is used. Constant of inertia of the whole system is given by

$$
\mathrm{H}_{\text {sys }}=\frac{\sum_{\mathrm{i}=1}^{\mathrm{N}} \mathrm{S}_{\mathrm{ni}} \mathrm{H}_{\mathrm{i}}}{\mathrm{S}_{\mathrm{n}, \mathrm{sys}}}
$$


Inertia of a whole grid can be calculated in form of kinetic energy stored in rotating machines. And its equation is given below:

$$
\mathrm{E}_{\mathrm{k}, \mathrm{sys}}=\mathrm{S}_{\mathrm{n}, \mathrm{sys}} \mathrm{H}_{\mathrm{sys}}=\sum_{\mathrm{i}=1}^{\mathrm{N}} \mathrm{S}_{\mathrm{ni}} \mathrm{H}_{\mathrm{i}} \text { [MW. s] }
$$

\section{1) Synthetic Inertia}

Synthetic inertia is explained by [9] which is given below:

Synthetic inertia: It is the inertia that is controllable with the help of electrical torque from a machine that is proportional to the RoCoF at the terminals of the generating unit.

Constant of synthetic inertia:

$$
\Delta P_{\mathrm{e}, i}=-2 H_{\mathrm{syn}, i} \frac{\mathrm{d} \omega_{\mathrm{t}}}{\mathrm{d} t} \omega_{t}
$$

To give an inertia response the torque must be proportional to RoCoF.

\section{Simulation AND RESUlts}

In this research we will consider two cases for primary control reserve studies to study the behavior of the frequency after a sudden contingency on the power system. First case is high reserve case in which their will be sufficient reserves present in the system to cater any sudden contingency like load increase or sudden generation loss. Second case is low reserve case in which the amount of reserve present in the system is less than the amount required for frequency stabilization. These cases are discussed separately containing two scenarios separately in each of the case along with simulation results showing frequency deviations for different renewable penetration levels in the system.

\section{A. Case 1}

In this case primary reserves present in the system will be of amount of $2500 \mathrm{MW}$ to withstand a sudden generation loss of $2000 \mathrm{MW}$ in the system, it may be forecast error or load increase on the system. Contingency may be in form of sudden generation loss, load increase and forecast error of renewable generation. There are four renewable penetration level considered in this simulation, which are $0 \%, 10 \%, 20 \%$ and $30 \%$. At these renewable penetration levels frequency behavior is checked. Also in this case FCR deployment rate considered are 20 seconds for first scenario and 10 seconds for second scenario.

\section{1) First Scenario}

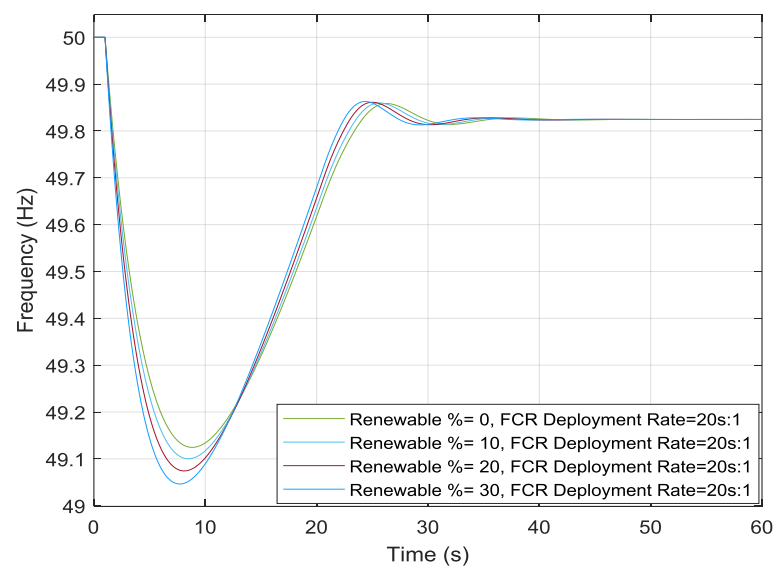

Figure 4. Simulation Result of Case 1, Scenario 1

Our main focus is renewable penetration, that is how it affect frequency of the power system. In the above figure 4 we can see that after a contingency, there is a deviation in the frequency of the system but primary reserve in the system catch the frequency and stabilize it at some point below its reference value $50 \mathrm{~Hz}$. In Pakistan power act 2005 [10] the UFLS (Under frequency load shedding) is set to be $49 \mathrm{~Hz}$, after this point load has to be shed to prevent system collapse and unstability. In this scenario FCR deployment is 20 seconds, mean all the reserve will be available within 20 seconds to cater any sudden contingency in the system. In this scenario all the renewable penetration levels frequency remains in UFLS point and the system doesn't goes into to load-shedding mode because all the frequency deviation curves shows that frequency is caught before $49 \mathrm{~Hz}$, that is before UFLS point.

\section{2) Second Scenario}

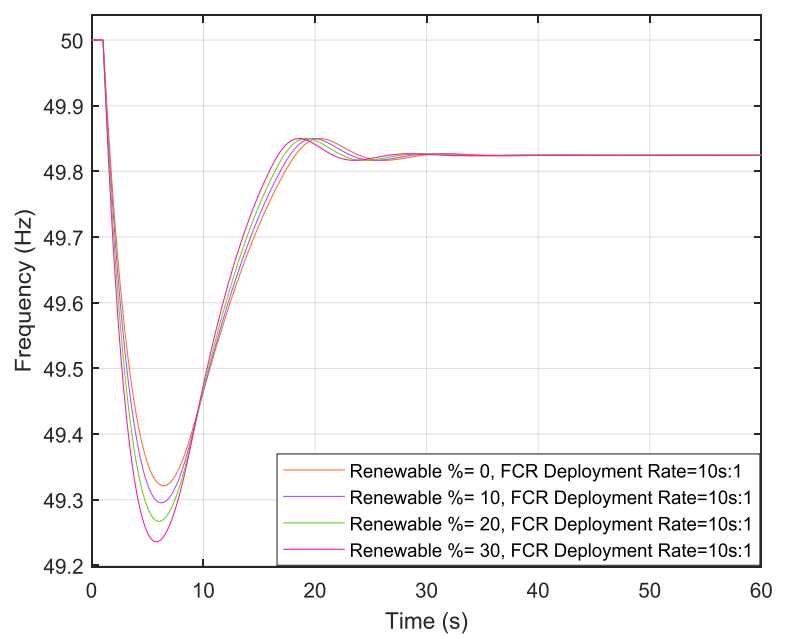

Figure 5. Simulation Result of Case 1, Scenario 2

In this simulation result FCR deployment rate is considered as 10 seconds to deploy primary reserves. Frequency deviation curves in this scenario are caught before $49.2 \mathrm{~Hz}$ so it is obvious that frequency deviation is caught before UFLS point and their will be no need of load shedding. So the primary reserves 
present are enough to stabilize the frequency to some point below its referency value $50 \mathrm{~Hz}$. For frequency to get back to its nominal value secondary reserves will be activated.

In this case two scenarios are discussed and after the comparison of these scenarios we can say that when FCR deployment rate is increased, frequency deviations are arrested earlier than the previous one. In this case FCR deployment rate considered for first scenario is 20 seconds and for second scenario is 10 seconds. In fisrt scenario the lowest possible deviation of frequency cure is approximately $49.05 \mathrm{~Hz}$ and in second scenario the lowest possible frequency curve is 49.24 $\mathrm{Hz}$. So from the above cases we can say that as the renewable penetration in a power system increases, system inertia decreases respectively and frequency deviation increases as inertia decreases. So from this we concluded that renewable penetration have a inverse impact on inertia of the system, as renewable penetration increases inertia of the system decreases and when renewable penetration decreases inertia of the system decreases respectively.

\section{B. Case 2}

In this case primary reserves present in the system will be less that the contingency appear in the system. Primary reserves available in the system will be $1800 \mathrm{MW}$, and the contingency appear in the system will be $2000 \mathrm{MW}$. In this case the system frequency deviate towards $48.5 \mathrm{~Hz}$ approximately which is too far below the UFLS point and the system will goes into load shedding. In this case frequency deployment rates will also be taken as 20 seconds and 10 seconds to deploy primary frequency control reserves. Inertia constant values in this case are also the same as previous case, so inertia of the system will also be the same in these scenarios as compared to the previous scenarios. Frequency deviation values in this case are higher as compared to the previous case.

\section{1) First Scenario}

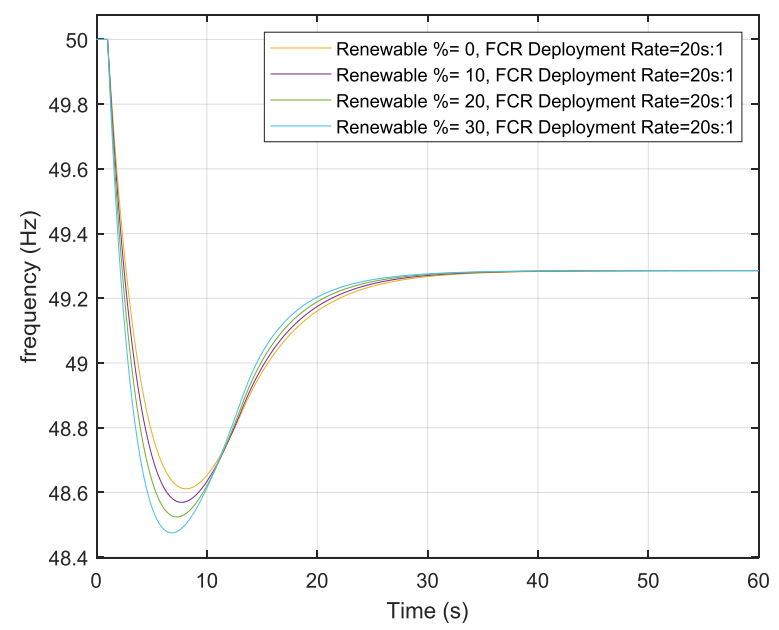

Figure 6. Simulation Result of Case 2, Scenario 1

In this scenario primary reserves are less than the contingency appeared in the system as compared to the previous case, therefore frequency. After the contingency system frequency starts to deviate from its nominal value, but the primary reserves available are not enough to catch frequency before ULFS point so the system will goes into load shedding to stabilize the frequency and frequency will be caught at approximately $48.48 \mathrm{~Hz}$ and will stabilize frequency at approximately $49.3 \mathrm{~Hz}$. And for frequency to get back to its nominal value secondary reserves will be activated. In this scenario frequency control reserves deployment rates is 20 seconds. In this scenario renewable energy penetration levels are also same as the previous scenarios like $0 \%, 10 \%, 20 \%$ and $30 \%$ renewable generation penetration in the Pakistan power system. For renewable penetration of $30 \%$ the frequency deviation is $48.48 \mathrm{~Hz}$ and for $20 \%$ penetration frequency deviation is $48.52 \mathrm{~Hz}$ and for $10 \%$ and $0 \%$ penetration frequency deviations are $48.57 \mathrm{~Hz}$ and $48.61 \mathrm{~Hz}$ respectively.

\section{2) Second Scenario}

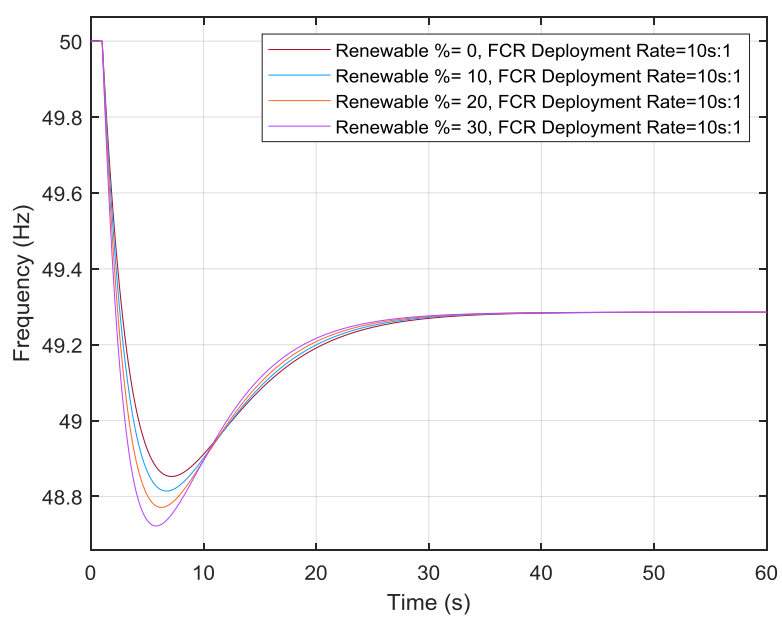

Figure 7. Simulation Result of Case 2, Scenario 2

In this scenario frequency deployment rate is 10 seconds, so frequency deviation is caught early in this scenario as compared to the scenario 1 in this case. For renewable penetration of $0 \%$ the frequency deviation value recorded is $48.85 \mathrm{~Hz}$, and for renewable penetration of $10 \%$ frequency deviation value recorded is $48.81 \mathrm{~Hz}$. For renewable penetration levels of $20 \%$ and $30 \%$ frequency deviation values recorded are $48.77 \mathrm{~Hz}$ and $48.72 \mathrm{~Hz}$ respectively. From the above both scenarios we concluded that as fast as the reserves deployment rate is, frequency of the power system is caught and stabilized fast. Also frequency dip in first scenario is large as compared to the second scenario because frequency control reserves deployment rate in first scenario is 10 seconds more and its response is late as compared to the second scenario which is 10 seconds. So in second scenario frequency is caught earlier than the first scenario in which frequency dip is larger. 


\section{FCR Deployment in both cases}

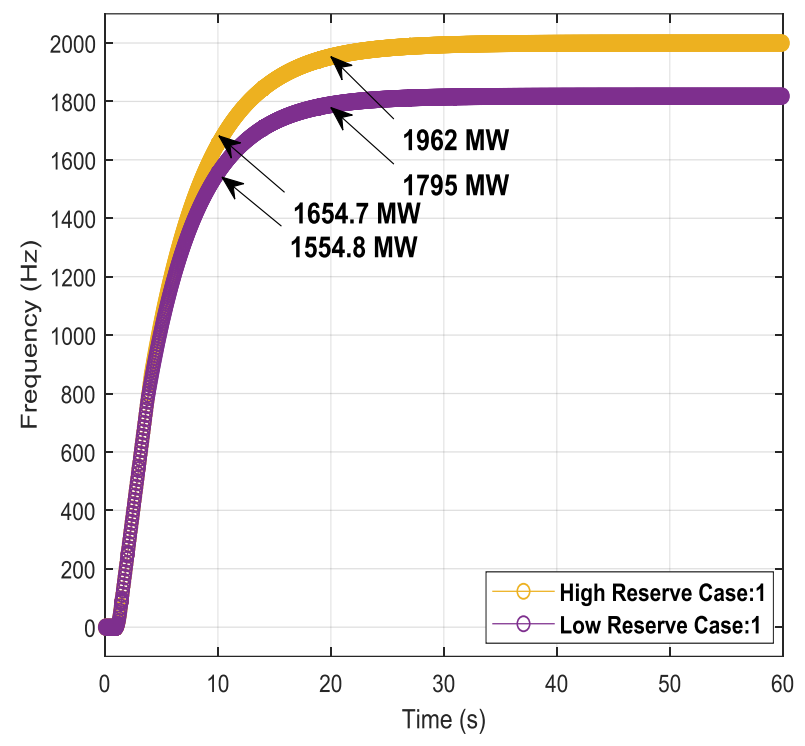

Figure 8. FCR Deployment in case 1 and 2

The above figure 8 shows frequency control reserves deployment in bothe cases in the simulations. In case 1 when primary reserves are deployed than the reserve power available to the power system at 10 seconds is $1654.7 \mathrm{MW}$ and at 20 seconds reserve power available to the power system is 1962 MW. And in case 2 when primary reserves are deployed then the reserve power available at 10 seconds to the power system is $1554.8 \mathrm{MW}$ and at 20 seconds reserve power available to the power system is $1795 \mathrm{MW}$.

\section{CONCUSLION}

As we know that addition of renewable generation to a power system creates variability and complexity and therefore all these problems are met with operating reserves to prevent large deviation in grid frequency. In Pakistan renewable penetration in national grid is also going to increase as compared to current situation. So, it was a need for frequency control studies in future Pakistan power scenarios. Focus of this research is the impact of renewable penetration on frequency of the grid and PFC reserves estimation in Pakistan national grid. Reserves deployment and its requirement in future Pakistan power scenarios are proposed. In high reserves case, when a sudden loss of generation occurs frequency starts to deviate from its nominal value. But due to high PFC reserves present in the system frequency deviation is arrested earlier and stabilized at a point lower than the reference value and in all the scenarios in first case not a single frequency curve passes the UFLS set point. In low reserves case, when we checked all the four scenarios for frequency deviations after a sudden contingency in the system. All the four frequency curves for different levels of renewable penetration, passes the UFLS set point and the system must shed some load to prevent any unwanted situation to appear in the system. In this case reserves were not enough to arrest frequency deviations before they pass the UFLS point but still frequency is stabilized at a point much lower than the reference value.

\section{REFERENCES}

[1] Hassan. Bevrani, Robust Power System Frequency Control, Second. Springer Cham Heidelberg New York Dordrecht London, 2009.

[2] European Network of Transmission System Operators (ENTSO-E), "ENTSO-E Operation Handbook (Policy 1)," no. Cc, p. 63, 2009.

[3] A. F. Guidelines, "Network Code on Load-Frequency Control and Reserves in line with the ACER Framework Guidelines on Electricity System Operation," vol. 6, no. February 2012, 2013.

[4] E. Ela, M. Milligan, and B. Kirby, "Operating Reserves and Variable Generation: A comprehensive review of current strategies, studies, and fundamental research on the impact that increased penetration of variable renewable generation has on power system operating reserves," no. August, pp. 1-103, 2011.

[5] K. Das, M. Litong-palima, P. Maule, and P. E. Sørensen, "Adequacy of Operating Reserves for Power Systems in Future European Wind Power Scenarios," 2015.

[6] K. Das, M. Altin, A. D. Hansen, P. E. Sorensen, and H. Abildgaard, "Primary reserve studies for high wind power penetrated systems," 2015 IEEE Eindhoven PowerTech, PowerTech 2015, 2015.

[7] N.2009c, "Procedure for Determining Interconnection Frequency Limits.," 2003.

[8] P. KUNDUR, "Power System Stability and Control." .

[9] R. Eriksson, N. Modig, and K. Elkington, "Synthetic inertia versus fast frequency response : a definition," vol. 12, pp. 507-514, 2018.

[10] E. P. Act, "Performance Standards (Distribution) Rules 2005 of Pakistan," vol. 1997, no. January, pp. 1-26, 2005. 